\title{
Belphégor
}

\section{Dumas, Alexandre. Gaule et France.}

\section{Vittorio Frigerio}

\section{OpenEdition}

\section{Journals}

Electronic version

URL: http://journals.openedition.org/belphegor/719

DOI: 10.4000/belphegor.719

ISSN: 1499-7185

\section{Publisher}

LPCM

\section{Electronic reference}

Vittorio Frigerio, « Dumas, Alexandre. Gaule et France. », Belphégor [Online], 14 | 2016, Online since 16 July 2016, connection on 24 September 2020. URL : http://journals.openedition.org/belphegor/719 ; DOI : https://doi.org/10.4000/belphegor.719

This text was automatically generated on 24 September 2020.

\section{(c) (i) (9)}

Belphégor est mis à disposition selon les termes de la Licence Creative Commons Attribution - Pas d'Utilisation Commerciale - Pas de Modification 4.0 International. 


\title{
Dumas, Alexandre. Gaule et France.
}

\author{
Vittorio Frigerio
}

\section{REFERENCES}

Dumas, Alexandre. Gaule et France. Édition de Julie Anselmini. Paris : Classiques Garnier, 2015. 336 p. ISBN : 978-2-8124-3485-3.

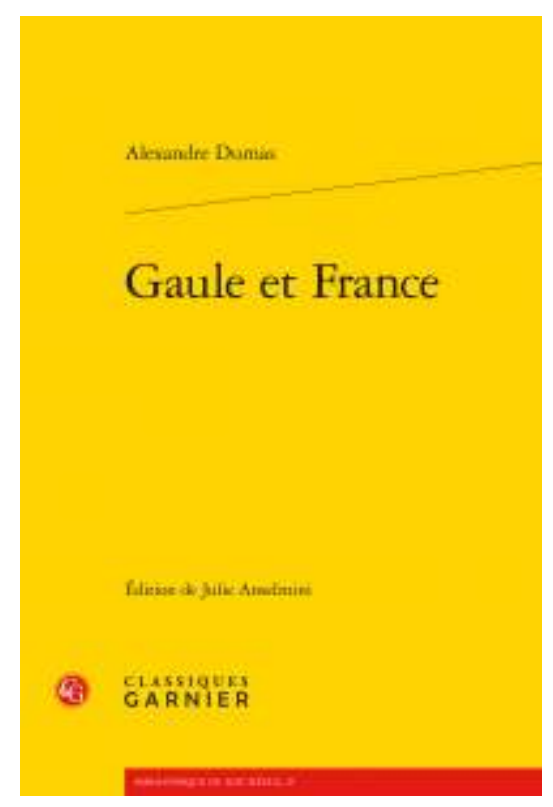

Depuis que les Cahiers Alexandre Dumas sont passés des éditions Encrage aux Classiques Garnier, cet éditeur, dont nous avons déjà signalé la publication du premier tome de la Correspondance générale de Dumas et le curieux ouvrage de Daniel Desormeaux, Alexandre Dumas, fabrique d'immortalité, semble consacrer de plus en plus de place au père indiscuté du roman populaire français. C'est maintenant grâce à l'initiative de Julie Anselmini, qui en édite le texte et fournit une utile introduction, que reparaît après bien des années d'absence des rayons des librairies un volume essentiel pour 
comprendre les motivations et la démarche du père des trois mousquetaires: Gaule et France.

2 Publié originalement en 1833 , on peut dire que ce volume est le seul ouvrage à proprement parler historique jamais écrit par Dumas - sans vouloir compter dans cette catégorie bien des explorations ultérieures, telles Louis XIV et son siècle ou Louis XV et sa cour, qui sont toutefois plutôt à l'enseigne de la compilation que de la véritable réflexion sur le développement et les raisons de l'histoire. Mais en 1833 Dumas n'était pas encore devenu le grand pourvoyeur de romans feuilletons pour les masses, produisant volume sur volume à un train d'enfer et descendant tout aussi rapidement l'échelle de la respectabilité littéraire. Il était encore une des jeunes énergies les plus remarquables derrière la victoire récente du romantisme sur la scène culturelle. Toutes les portes lui paraissaient ouvertes, ou susceptibles de pouvoir être enfoncées sans trop de précautions si on se hasardait à les lui tenir fermées. Gaule et France semble justement être une tentative d'enfoncer une porte de plus - celle des études historiques stricto sensu - et l'accueil très mitigé qu'on lui fit contribua vraisemblablement beaucoup à orienter l'activité de l'écrivain vers les romans qui, pour finir, devaient faire son authentique célébrité et le mener de nos jours jusqu'au Panthéon.

CEuvre devant sortir en même temps que commence à se publier, avec un tout autre impact et un succès bien différent, l'Histoire de France de Michelet, Gaule et France tente d'offrir un résumé saisissant de la naissance, de la croissance et du développement de la nation française, de l'antiquité la plus reculée jusqu'au XIV e siècle. L'entreprise est bien marquée par des besoins qui étaient ceux de son temps, celui de la Monarchie de Juillet, et surtout par la volonté de fouiller dans les époques enfouies pour y retrouver les matériaux nécessaires à la stabilisation d'un pays qui en l'espace de peu de décennies avait passé par des bouleversements politiques et sociaux énormes. Mais Dumas ne se limite pas à cela. Anselmini cite avec pertinence dans la préface une phrase clef pour comprendre sa démarche: "c'est dans le passé qu'il faut chercher le secret de l'avenir".

Dumas tente à travers cet ouvrage de se faire accepter non seulement comme écrivain de théâtre ou romancier débutant de talent, mais également comme historien. Il puise à des sources on ne peut plus nombreuses (identifiées et rappelées par Anselmini dans son avant-propos), qu'il ne se prive pas de citer copieusement ou d'indiquer dans d'abondantes notes de bas de page. Surtout, il épouse les thèses d'Augustin Thierry, à qui il emprunte également la notion de «races » différentes - les Francs et les Galloromains - qui se disputeraient le pouvoir et qui, par leur intégration, finiraient par construire le pays actuel. Théorie par ailleurs évocatrice de la vision de l'histoire de l'Angleterre à l'époque des invasions saxonnes, propagée par Walter Scott - le romancier que tout le monde en France en ce moment-là voulait plus ou moins imiter et à laquelle Eugène Sue donnera plus tard une tournure plus nettement sociale dans ses Mystères du peuple.

5 Anselmini restitue à ce livre son rôle fondamental de « texte matriciel » (p. 23), imbu de notions providentialistes et progressistes, duquel surgira plus tard l'ensemble de l'œuvre romanesque de l'auteur. Cette vaste chronique de l'émancipation du peuple, à l'intérieur de laquelle se construit, en même temps que le livre s'écrit, la philosophie essentiellement libérale de l'auteur, mérite donc d'être lue à la fois pour l'importance qu'elle a eu dans l'ensemble de l'œuvre dumasienne, que comme un document important pour restituer les débats de l'époque autour de la nature et de la fonction de 
l'histoire. On ne peut par conséquent que se réjouir de cette initiative, qui permettra à de nouveaux lecteurs de découvrir un texte aux implications fascinantes, présenté ici en une édition soignée qui comprend, en plus d'un «descriptif de deux recueils de sources dont s'est servi Dumas ", un abondant dossier détaillant la "réception de Gaule et France dans la presse ", ainsi qu'une bibliographie et un index fort utiles.

\section{AUTHOR}

\section{VITTORIO FRIGERIO}

Dalhousie University 